\title{
Debatedor
}

\section{Duas políticas, duas vigilâncias, duas caras}

Two policies, two surveillances, two faces

Luiz Carlos Fadel de Vasconcellos ${ }^{1}$

O convite para debater o artigo de Danilo, Lacaz, Marçal e Rodolfo (COSTA; LACAZ; JAKSON FILHO; VILELA, 2013), a par de me honrar, deixou-me apreensivo pelos desafios contidos. Um deles, o fato de ainda prevalecer no campo da saúde do trabalhador (ST) a imensidade das perdas humanas e dos obstáculos políticos institucionais que exigem um alinhamento dos autores às expectativas otimistas. Os autores, além do respeito que merecem pelo que são, pensadores e formuladores de boa parte do acervo acumulado no campo da ST, usam de forma magistral esse acúmulo, o que torna difícil acrescer algo ao que propõem no texto. Outro desafio foi o convite estendido para que eu comentasse também os dois textos debatedores do número anterior, um deles do professor Minayo-Gómez (p. 21-25), com a credencial de ser um dos principais pensadores da ST, referência obrigatória no dimensionamento conceitual do campo, e o outro de Claudia Chiavegatto em parceria com Eduardo Algranti (p. 25-27), pesquisador histórico da área e das pneumoconioses. Em todos os textos vimos observações contundentes, instigantes e polêmicas. Lendo-os e relendo-os com atenção e interesse, direcionei minha análise para alguns dos pontos abordados. Considerando que os textos têm como objeto central os desafios para uma

${ }^{1}$ Escola Nacional de Saúde Pública, Fundação Oswaldo Cruz. Rio de janeiro, RJ, Brasil. E-mail: elfadel@globo.com. 
política pública de saúde do trabalhador no SUS, é preciso ressaltar que os formatos apresentados, com suas limitações físicas, não possibilitariam um maior aprofundamento, tal a complexidade do tema. O mesmo vale para esta minha reflexão. De qualquer modo, tentei caminhar por vertentes do que foi dito, mas merece ser enfatizado, inclusive para valorizar o que foi dito.

A partir do artigo principal (COSTA; LACAZ; JAKSON FILHO; VILELA, 2013), observamos uma análise atual, densa, pertinente e propositiva do que se deve ter em conta na construção de uma política de ST. Como recordatório, trago uma brevíssima síntese do que foi dito e debatido. Partindo da contextualização do modelo socioeconômico vigente no mundo globalizado, com todas as consequências para o mundo do trabalho, cuja essência se contradiz com o ideário da ST, para autores e debatedores essa política tem como desafios: ombrear indicadores nacionais com os internacionais; enfrentar os dados submersos no setor informal; olhar para o novo perfil de morbidade; operar a interdisciplinaridade e a intersetorialidade, incorporando trabalhadores como sujeitos de ação; situar a vigilância em ST no centro da política, inclusive nas políticas de desenvolvimento; enfrentar os problemas estruturais dos serviços de ST, seja na gestão, na instabilidade contratual dos profissionais, na sua formação ou na relação com o controle social; e, finalmente, enfrentar as dubiedades e as indefinições que colocam as ações de ST fora do eixo central das "funções essenciais do Estado provedor". Dessas variáveis elegi, três aspectos a que denomino: (1) as duas políticas; (2) as duas vigilâncias; (3) as duas caras.

(1) As duas políticas:

Ao erigir duas políticas de saúde do trabalhador ${ }^{2}$, o Estado brasileiro assumiu sua intenção de ter NENHUMA política de Estado para a área. Quem tem duas não tem uma. Demonstra-se que se cria uma coisa com o SUS e outra coisa no SUS. É nenhuma política de Estado porquanto fragmenta, titubeia, virtualiza, mostra um Estado partido e envergonhado de assumir uma direcionalidade una de suas estruturas. Como resposta contra-hegemônica a este "buraco" político do Estado, existe uma política de fato (mais propriamente um conjunto de ações de fato) no âmbito do SUS, mas compreensivelmente débil, frágil, pontual e pouco resolutiva, a despeito do esforço feito pela Coordenação Nacional de Saúde do Trabalhador do SUS e por uma parcela expressiva da Renast. É nela que se abriga "o povo da saúde do trabalhador", em que reside a resistência à realidade imposta pela conjuntura tão bem assinalada no artigo principal.

Enquanto diversas corporações e instituições se mantiverem reativas e não compreenderem que o SUS é o responsável pela condução das políticas de saúde pública no Brasil e que a saúde do trabalhador, no seu todo, é uma política de saúde pública, andaremos sem um marco referencial legal e legítimo de política de Estado estruturante para a área. Essas corporações e instituições reativas não se situam só no campo da previdência e do trabalho, como pode parecer. Estão inseridas no próprio setor saúde, especialmente nas suas instâncias de gestão, em muitos dos profissionais de saúde da rede como um todo, na Anvisa, no controle social e, fora do setor saúde, nos outros ministérios, nos Poderes Legislativo, Judiciário e, claro, nos setores empresariais.

Ter o SUS como o condutor da política não significa excluir outros setores do Estado quanto às suas responsabilidades em ST, ao contrário, significa trazer para o campo da saúde pública a conjugação de todas as instâncias em uma perspectiva sistêmica, como a própria ideia de Sistema Único de Saúde prevê. Prevê, mas não faz. Significa, ainda, introduzir a categoria trabalho na perspectiva sistêmica das políticas desenvolvimentistas, tendo a saúde como foco de dignificação e valorização da vida. Nessa perspectiva, tantas são as possibilidades de uma política de Estado aglutinadora das diversas questões: interlocução em uma esfera única do Estado que abranja a totalidade de seus aparelhos; conjugação de ações e otimização de recursos financeiros e humanos; dissolução de barreiras institucionais (tais como as informações previdenciárias e as ações de vigilância citadas no debate); planejamento de ações conjugadas de Estado; incorporação da área de saúde, trabalho e ambiente aos planos de desenvolvimento; viabilização do olhar do Estado sobre as cadeias produtivas que alcancem o trabalho informal, infantil e escravo; e, entre outras, utilização da capilaridade epidemiológica do setor saúde para que as ações cheguem a todo o território brasileiro.

Para isso, é bom lembrar que o SUS é mais do que o setor de saúde propriamente dito e deste vai além, enquanto sistema. Portanto, para um único problema, o da saúde do trabalhador, uma única política e uma única solução de planejamento de Estado para um enfrentamento de Estado.

${ }^{2}$ Política Nacional de Segurança e de Saúde do Trabalhador (BRASIL, 2011) e Política Nacional da Saúde do Trabalhador e da Trabalhadora (BRASIL, 2012) 
(2) as duas vigilâncias:

Existem duas vigilâncias em ST: a da intenção e a do gesto. A da intenção frequenta o discurso da Renast, os textos acadêmicos e muito da expectativa do "fazer alguma coisa". Já a vigilância do gesto, valendo-me do que foi debatido, é aquela que depende de iniciativas pontuais, muitas vezes voluntaristas, de pessoas engajadas, comprometidas e abnegadas: o "povo da ST". Mas essas iniciativas tendem a ser aleatórias, muitas vezes redundantes e dispersivas, interrompíveis, pouco resolutivas e muito pouco transformadoras. Por outro lado, aqui, na vigilância do gesto, reside a exceção à regra da ST, ou seja, é onde efetivamente se consegue "fazer alguma coisa". Entendo que a vigilância da intenção depende da política de Estado, no caso NENHUMA, e a vigilância do gesto na política de fato (ou do fato), aquela que faz alguma coisa. Nossa luta, inclusive na produção acadêmica de conhecimentos, é por fazer valer as duas, mas a do gesto já está posta, resta implementá-la enquanto trincheira de resistência.

Falar sobre isso demandaria espaço e tempo, mas podemos pensar em alguns passos factíveis: $1^{\underline{0}}$ - urge uma capacitação maciça de agentes públicos de vigilância em todo o Brasil, com o engajamento de todos os Cerests da Renast a partir de um método pedagógico inclusivo dos agentes, com capacidade de ser reproduzido, aplicado e apropriado de forma rotineira no cotidiano dos serviços; e $2^{\circ}$ - urge ir bem além de implicar a atenção básica como ponto de partida, como foi aventado no segundo texto debatedor, mas sim a rede como um todo e as demais estruturas afins de Estado, em uma abordagem por complexidade da ação, situando os Cerests como polos produtores de conhecimentos para a transformação da ST, articulados especialmente com as instâncias de ensino e pesquisa, em cada nível local. Um projeto deste tipo foi iniciado visando à formação de multiplicadores de Visat até meados de 2014 e a formação maciça de agentes na rede SUS no biênio 2014-2015, especialmente nas regiões Centro-Oeste, Norte e Nordeste. Trata-se de mais uma tentativa de aprimorar a vigilância do gesto e encorpar a resistência que "faz alguma coisa", enquanto lutamos por uma vigilância de ST como política de Estado.

\section{Referências}

BRASIL. Decreto nº 7.602/2011, de 07 de novembro de 2011. Dispõe sobre a Política Nacional de Segurança e Saúde no Trabalho. Diário Oficial [da] República Federativa do Brasil, 08 de novembro de 2011. Disponível em: < https://www.planalto.gov.br/
(3) as duas caras:

O Estado brasileiro tem duas caras quando olha para a ST. Uma finge que enxerga. A outra é cega. Os sucessivos governos utilizam colírios que não lhes facultam a visão. Aqui, a luta é mais complexa, pois depende do enfrentamento, ora de alguns dogmas, ora de práticas enraizadas, ora de instituições conservadoras, isso para não falar do poder econômico e da lógica mercantil de condução das políticas públicas. Algumas delas: a não inserção da categoria trabalho como determinante social central da saúde pública; a cultura da insalubridade como um direito inquestionável; a desfocalização do trabalho na ideologia da sustentabilidade, em suas formulações teóricas e nas suas práticas; a cooptação da classe trabalhadora pela "lógica" internacional do tripartismo; a desvinculação política, institucional e simbólica da violência social com o trabalho; a exclusão da ST da agenda de prioridades da luta sindical; a representação legislativa maciça de aliados aos setores empresariais conservadores, como o do agronegócio, por exemplo; a visão jurídica distorcida da ST no SUS e sua missão de vigilância da saúde; a formação dos distintos profissionais que atuam nas relações saúde-trabalho voltados para um mercado em que defender a saúde é desprezado e mesmo um contrassenso à sua lógica; a inexistência de uma pedagogia de inclusão do trabalho como símbolo positivo no imaginário infantil; uma "ética" do mercado sobrepujante a uma ética da vida no trabalho. Cada uma dessas variáveis mereceria uma discussão que ainda está por ser aprofundada na produção de conhecimentos do campo. Esses são alguns dos desafios de um debate sobre a verdadeira face do Estado brasileiro nesta questão.

Enfim, a iniciativa da RBSO de provocar essas questões e trazê-las ao debate acadêmico, além de louvável e oportuna, é instigante e nos deixa a boa sensação de insuficiência. Fica a sugestão para que a revista mantenha um espaço permanente para o tema dos desafios da política de saúde do trabalhador no Brasil. ccivil 03/ ato2011-2014/2011/decreto/d7602.htm> Acesso em: 5 dez. 2013.

. Ministério da Saúde. Portaria n⿳o 1.823, de 23 de agosto de 2012. Institui a Política Nacional de Saúde do Trabalhador e da Trabalhadora. Diário 
Oficial [da] República Federativa do Brasil, ํำ 165,

Seção I, p. 46-51, 24 de agosto de 2012. Disponível em:

$<$ http://bvsms.saude.gov.br/bvs/saudelegis/gm/2012/

prt1823_23_08_2012.html>. Acesso em: 5 dez. 2013.
COSTA, D.; LACAZ, F. A. C.; JAKSON FILHO, J. M.;

VILELA, R. A. G. Saúde do Trabalhador no SUS: desafios para uma política pública. Revista Brasileira de Saúde Ocupacional, São Paulo, v. 38, n. 127, 11-30, 2013.

Recebido: 26/08/2013

Aprovado: 17/09/2013 